\title{
Technologies of ironic revelation: enacting consumers in
}

neuromarkets ${ }^{1}$ [final draft post-refereeing]

\section{Tanja Schneider and Steve Woolgar}

Institute for Science, Innovation and Society (InSIS), University of Oxford, Oxford, United Kingdom

To cite this article: Tanja Schneider \& Steve Woolgar (2012) Technologies of ironic revelation: enacting consumers in neuromarkets, Consumption Markets \& Culture, 15:2, 169-189, DOI: $10.1080 / 10253866.2012 .654959$

Correspondence address:

Institute for Science, Innovation and Society, Saïd Business School, University of Oxford, Park End Street, Oxford OX1 1HP.

Email address of corresponding author: tanja.schneider@sbs.ox.ac.uk

\footnotetext{
${ }^{1}$ Our thanks to Lucy Bartlett for help in preparing this paper and for helpful comments on earlier versions from CF Helgesson and Paddy Barwise. Also to participants at the $1^{\text {st }}$ Interdisciplinary Market Studies Workshop, Sigtuna, Sweden, June 3-4 2010, and to members of Tema T, Linköping University, Sweden.
} 


\section{Technologies of ironic revelation: enacting consumers in neuromarkets}

Neuroscience is increasingly considered as a possible basis for new business and management practices. A prominent example of this trend is neuromarketing - a relatively new form of market and consumer research that applies neuroscience to marketing by employing brain imaging or measurement technology to anticipate consumers' response to, for instance, products, packaging or advertising. In this paper we draw attention to the ways in which certain neuromarketing technologies simultaneously reveal and enact a particular version of the consumer. The revelation is ironic in the sense that it entails the construction of a contrast between what appears to be the case - consumers' accounts of why they prefer certain products over others - and what can be shown to be the case as a result of the application of the technology - the hidden or concealed truth. This contrast structure characterises much of the academic and popular literature on neuromarketing, and helps explain the distribution of accountability relations associated with assessments of its effectiveness.

Keywords: neuromarketing; technologies of ironic revelation; consumers; accountability; market research, science and technology studies 


\section{Introduction}

This paper aims to contribute to understanding marketing's market-making capacity. We take as our starting point the emergence and growing prominence of a new form of market and consumer research, so-called neuromarketing. Neuromarketing - the application of neuroscience to marketing by employing brain imaging or measurement technology to anticipate consumers' response to, for instance, products, packaging or advertising - is the latest in a series of means promoted by marketers as a way of understanding consumer behaviour and of countering the problem of new product failure. Based on a exploratory study of the young field of neuromarketing, we examine in this paper what possible understandings of the consumer are enacted in (neuro)market(ing) practice.

We take our cue from existing research in the growing field of social studies of market that stresses the need to conceptualize, possibly multiple, efforts to preconfigure actors (see Andersson, Aspenberg and Kjellberg 2008, 70). For instance, Araujo notes that the consumer "no longer appears as a singular entity modelled by a single unified logic, but as a multi-faceted entity modelled according to a variety of criteria not easily amenable to a single set of calculations' (Araujo 2007, 220). Beyond the immediate field of market studies and more closely related to the topic of our research into the encounters of neuroscience and social science, researchers have suggested that the current prominence of neuroscientific explanations and the uptake of neuroscientific techniques in a variety of disciplines (e.g. neurolaw, neurotheology, neuroeconomics) has led not only to new conceptualisations of specific subject positions but to new conceptualisations of personhood in general (Rose 2003, 2006; Ortega and Vidal 2007; Maasen and Sutter 2007). For Rose $(2003,2006)$ the brain occupies a privileged space within contemporary (somatic) culture which he concludes 
has led to a depiction of beliefs, desires, behaviour and emotions in wholly neurochemical terms. Relatedly, Ortega and Vidal suggest that in contemporary (neuro)society, humans seem to be essentially constituted by the brain. According to them we are currently faced with a new form of personhood - or rather brainhood which they refer to as the "cerebral subject"1 (Vidal 2005; Ortega and Vidal 2007; Vidal 2009). They suggest that with the growing prominence of the neurosciences it is within the brain that a human being's essence - his or her personal identity - can be found, thence understood as a cerebral identity.

Other research has found that alternative conceptualisations of, for instance, patients and children emerge when neuroscience is taken up in fields such as medicine and pedagogy (Nadesan 2002; Cohn 2008). For example, Nadesan (2002) suggests that marketing's uptake of neuroscientific research into infant neural development (neuropedagogy), in particular for the development of educational toys which are said to stimulate infant neural development, mobilises a new subject position namely, the entrepreneurial infant - 'the antecedent condition/position of the entrepreneurial subject' $(2002,418)$. She argues that the discourse of brain science suggests that infant brains can be engineered for excellence if the correct stimulation is provided during critical periods of development. This discourse appeals to many parents who want to prepare and steer their children towards their future role as knowledge workers.

More recently Schüll and Zaloom (2011) have suggested that the field of neuroeconomics has the potential fundamentally to reconfigure human choice-making behaviour and as such challenge economic modelling based on the assumption that the human being is a rational actor - homo oeconomicus - who calculates her choices to maximise profit. This resonates with Callon's earlier observation that the emergence of calculative agencies is the product of framing. By this he means that agents are 
extricated from the network of interactions and pushed '... onto a clearly demarcated 'stage' which has been specially prepared and fitted out' (1998, 253). Relatedly, Callon highlights the role of marketing in setting up and deploying framing devices of calculative agencies $(1998,26)$. He proposes that marketing establishes (material) practices (e.g., the marketing mix $=4$ Ps: product, price, place, promotion) which have an impact on the consumer and argues that the consumer is the consequence rather than the cause of these practices $(1998,27)$.

Our analysis of how neuroscience enacts conceptualisations of the consumer has been motivated by the accounts reviewed above. We wonder, what are the experts' conceptualisations of the consumer emerging when neuroscience meets marketing? And how can existing research in the field of market studies assist us in this inquiry? The paper addresses the latter questions first by reviewing the different ways in which markets are problematised in the literature and by proposing that these differences align with different general analytic perspectives in science and technology studies (STS). This alignment is used to identify a particular feature of recent market studies, namely the ways in which the figure of the consumer is enacted through what we call technologies of ironic revelation. By this we mean that certain technologies (in our case brain imaging and measuring devices) simultaneously reveal and enact a particular version of the consumer that depends on an achieved contrast between what appears to be the case - consumers' accounts of why they prefer certain products over others and what can be shown to be the case as a result of the application of the technology the hidden or concealed truth. The revelation is ironic in the technical sense that justification for the use of these technologies depends on a constructed incongruity between what is expected and what actually is the case. 
In order to illustrate the operation and consequences of technologies of ironic revelation, the paper reports a preliminary investigation of how a new understanding of consumers is enacted in neuromarketing research. Using textual analysis, we examine the debate around neuromarketing's potential as depicted in academic journals, popular and media accounts. We then draw on this exploratory analysis to propose that the force of ironic revelation can be understood in terms of the shifts in accountability relations between operators and subjects of these technologies, which these technologies perform, and the ways in which changes in contexts of evaluation provide ways of deflecting criticisms about technical inadequacy.

\section{Problematising the market}

In the burgeoning research literature, the concept of the market has been problematised in a variety of ways. In broad terms, it is possible to discern a shift in conceptualisations of the market between three main perspectives: from a) markets understood as economic relations between rational actors (individuals, organisations, firms) to b) markets understood as a) previously but with the addition of human, social, cultural 'factors' and/or 'dimensions', to c) a broad spectrum of approaches which can be subsumed under the 'pragmatic turn'; perspectives which portray markets as constituted in and through the 'social'.

This last 'pragmatic turn' to markets prioritises attention to mechanisms, which are variously described as the constitution, performance and enactment of markets. On the whole, the pragmatic turn of perspective c) favours these latter descriptions of market mechanisms, whereas perspective b) more commonly uses the term 'construction'. These mechanisms or devices are said to be effected through various material and discursive assemblages, which include financial models, mathematical 
formulae, technologies and ordinary market devices, such as shopping trolleys, various scalar devices and so on (Cochoy 1998; MacKenzie 2003; Cochoy 2007; MacKenzie, Muniesa, and Siu 2007; Cochoy 2008). In summary terms, the pragmatic turn portrays markets as practical accomplishments (Kjellberg and Helgesson 2007).

It is instructive to consider the move between these perspectives, from a) to b) to c), as roughly analogous to key shifts between early approaches to the social analysis of scientific knowledge. In this schema, the understanding of the market as economic relations between rational actors corresponds to the 'received view' of science. The subsequent addition of 'social factors' corresponds to the weak programme in the sociology of scientific knowledge (SSK), where 'weak' connotes the criticism that these kinds of analysis of science fell short of trying to explain the nature and content of scientific knowledge. Much was said about social relations (institutions, roles, structures) between scientists but little was said about how these affect the nature and direction of scientific knowledge itself. The third broad perspective, the 'strong programme' in sociology of scientific knowledge, encouraged ways of addressing the 'social' basis of the epistemic status of scientific knowledge.

This simple three part schema does scant justice to the enormous variety of science and technology studies (STS) and for the ease of comparison neglects theoretical developments in STS such as generalised symmetry ${ }^{2}$. In particular, this rendering of the 'strong programme' subsumes a whole series of different ways in which STS has attempted to cash out the ideas of contingency and performativity. Nonetheless, for our purposes, the schema makes the point that successive moves in the socialising of science can be understood as a series of successive challenges to (or provocations on) essentialism. For example, each stage of the tripartite typology can be understood as a successive attempt to overcome, or fashion an appropriate challenge to, 
the long standing legacy of the deeply entrenched divide between the social and the technical (see Shapin and Schaffer 1985; Latour 1993).

This parallel between analytic shifts in market conceptualisations and those in STS emphasises that STS provides market practices with a resource for drawing on equivalent efforts and attempts in STS. More important for our purposes, the successive shifts between perspectives remind us that more can always be done in challenging essentialism and taken for granted categories. In this spirit we note that the pragmatic turn in market studies gives increasing emphasis to the configuration of market actors. Whereas previous approaches tended to concentrate on the role of the producer rather than consumer in constituting markets, recent work discusses how a whole variety of market agencies, including buyers and shoppers, are configured in market practice (Callon 1998a; Barrey, Cochoy, and Dubuisson-Quellier 2000; Andersson, Aspenberg, and Kjellberg 2008; Callon, Millo, and Muniesa 2008; Cochoy 2008; Kjellberg 2008). A well known example of the constitution of 'actors' by market devices is Cochoy's (2008) description of the ways in which a shopping cart constructs a certain kind of 'shopper'. Arguably, however, more research is needed on how different varieties of economic agency are enacted and the role advertising agencies and market research companies play in the process (e.g. Hackley 2002). For example, in recent years we have heard much about the rise of the increasingly competent and savvy consumer (Macdonald and Uncles 2007; Cova and Cova, this issue). As part of this claimed rise of marketing literacy, we would expect some sources of resistance to the straightforward enactment of the passive consumer. What then accounts for the constitution of consumers as 'savvy' or 'passive'? By looking at neuromarketing in practice, we aim to show the importance of the distribution of accountability relations for explaining the success of revelatory technologies in enacting conceptualisations of the consumer as 
rather passive and non-knowledgeable. In the next section we provide an overview on the recent neuro-turn in marketing and discuss one example of neuromarketing research in more detail before analysing neuromarketing's claims to revolutionise market and consumer research.

\section{The neuro-turn in marketing}

Neuromarketing is much vaunted as a new form of market and consumer research (e.g., Lee, Broderick, and Chamberlain 2007; Senior and Lee 2008; Ariely and Berns 2010). As mentioned above, it draws upon a variety of brain imaging technologies including: functional magnetic resonance imaging (fMRI); electroencephalography (EEG); magnetoencephalography (MEG); steady state topography (SST); and positron emission tomography (PET). Brain imaging is used to assess which areas of the brain are active in relation to specific tasks undertaken by the subject, and what is the extent of this activity. This is done, for example, in relation to the visual perception of the colour or shapes of products, or the effect on the brain of certain smells and odours. In the case of fMRI the extent of brain activity is inferred from changes in the amount of blood flow in specific areas of the brain. Although the original measurement information is numerical, not visual, the protocol for presenting this information typically represents this information through use of various colours. It is this which enables the subsequent locution, in a telling use of metaphor, that the brain 'lights up' in response to certain forms of stimulation.

In addition to the brain imaging technologies listed above, more and different techniques are being subsumed under the 'neuromarketing' label. A look at neuromarketing research and consultancy websites shows that proponents of techniques such as eye tracking and biometric data (that is, measurement of heart rate, skin 
conductance, respiration, movement, muscle, pupil dilation and pulse volume) are increasingly self describing their work as neuromarketing. ${ }^{3}$ This allows the participation in the new enterprise of experts in previously discarded marketing techniques. This kind of band wagon effect means that neuromarketing is not simply an alternative, competitor to previous ways of marketing, it instead accrues supporters of those previous efforts through their own re-definition of their skills and experience.

Neuromarketing is controversial both in terms of ethics and reliability. From the point of view of ethics, some have argued that neuromarketing is a wholly inappropriate intervention into a person's sub-consciousness. The implication is that it is somehow underhand to access parts of a person's being over which they themselves do not have full control. This mirrors objections to previous market research techniques, for example, Motivation Research, which were said to take advantage of the consumer by accessing and manipulating features of their consciousness in an underhand manner (e.g., Packard 1957/1981; Schwarzkopf and Gries 2010) ${ }^{4}$. At the same time, it seems this form of ethical objection to neuromarketing may already be waning somewhat. A brief look at marketing trade magazines shows that although the figure of the brain was absent even a couple of years ago, contemporary issues (e.g., Admap Magazine January 2010) are replete with pictures of brain scans. In those publications at least, and over the course of the last eight years, the brain has moved from being an unmentionable object of taboo to a commonly acceptable icon of cutting edge marketing activity.

The reliability of neuromarketing's use of brain imaging technologies is much debated (Editorial 2004; Medina 2004; Fugate 2007; Wilson, Gaines, and Hill 2008). An interesting twist is that questions about the reliability of the technology are finessed by appeal to the outcomes of this form of marketing (Ariely and Berns 2010). As we discuss in more detail below, this suggests an important shift in the distribution of 
accountability relations associated with the genesis and use of neuroscientific results. Whereas we might imagine that neuroscience research communities comprise certain criteria of research adequacy (however, see the recent report by ARF 2011), what counts as working is here posited as something that might be judged on results outside that community, in the context of use.

Questions about ethics and reliability have not yet proved significantly problematic to the central claim of neuromarketing, namely that it offers a novel source of detailed knowledge about consumer preferences and about what marketing activities stimulate consumers' purchasing behaviour (but see Wilson, Gaines, and Hill 2008). Such knowledge is presented as vital to improving the likely success of products. Notwithstanding the (separate) problem of reliability in interpreting brain imaging results, proponents of neuromarketing champion its purported advantages in circumventing the difficulty of relying upon the consumer's own views. It is offered as a technology that can be used to help know the mind of the unknowing consumer and that 'reveals hidden information' that is not accessible through other forms of market research (Ariely and Berns 2010). These insights, it is said, will help substantially reduce the failure of new products (or in other words, increase sales). Based on neuromarketing's potential use-value a number of firms ${ }^{5}$ have sought advice from neuromarketing researchers and consultants and neuromarketing is enjoying substantial investment by market research companies. Thus, companies such as Nielsen or Millward Brown have either made an acquisition of a firm offering neuromarketing research and consultancy services or are building up their own in-house department offering applied neuroscience to marketing problems. Nevertheless it is currently unclear whether or not neuromarketing will become widely accepted. 


\section{'Doing' neuromarketing}

How then is neuromarketing done? In order to identify some of its key features, we consider the case of advertising effectiveness. Questions about the effectiveness of advertising take place in the context of dramatic recent changes in the various ways in which people consume media. Different channels, free to air, pay per view, on demand viewing and so on generate important questions for marketers about how to place advertisements successfully, and how to price the advertisements. Answers to these questions are especially important when the scale of investment is realised: the cost of showing a 30 second advertisement during the televising of the 2010 Super Bowl was purportedly 3 million US dollars. Those purchasing advertising space at this level of expenditure would be keen to know whether or not they are getting value for money. 'If you are going to spend $\$ 3$ million for a 30 second ad you want to know how effective it is. ${ }^{6}$ Neuromarketing claims to offer a reliable way of assessing advertising effectiveness based on objective neurological evidence.

Sands Research Inc., a U.S. based neuromarketing consultancy that offers its services globally, report their own techniques and measures of advertising effectiveness using neuromarketing. They especially emphasise the importance of the length of time which it takes adverts to have an effect on the viewer. Thus, one slide in the Sands online presentation, entitled 'Just a Few Seconds to Engage', features a multi-coloured cross section of the cranium with the legend: 'The critical first seconds - the Viewer's frontal lobe (red) which performs executive functions related to memory and planning communicates to the parietal lobe (yellow) that integrates sensory information which in response determines the level of brain activity to be deployed.'

The Sands presentation also includes a slide entitled 'Methods' which explains that participants in the study were 'fitted with a 68 channel (electrode sites on the scalp) 
EEG Cap and light weight Eye tracking glasses with two cameras. One directed at the participants' pupil and the other at their viewing target.' The participants viewed the TVCMs (Television Commercial Messages) individually 'in a relaxed living room type setting and sitting in a comfortable lounge chair.'

These methods are used to determine the extent of viewer 'engagement'. A graph shows how the extent of electrical activity in the brain varies over time with the passage of the advert. 'Within 800 milliseconds the lobe communication takes place.' 'Within 4 seconds the viewer's decision is made on how much engagement to devote to the material presented.' 'After the 800 millisecond spike and follow up 4 second decision window, the brainwave signal activity will stay on a high plateau (sustained power function) if the viewer is engaged or decline or fluctuate, sometimes rapidly, if viewer is inattentive.' It is asserted that 'increased activity directly correlates to increased recall'.

In the case of the 2010 Coke Heist advert, a measure of engagement $(\mathrm{NEF}=$ the Neuro Engagement Factor) is adduced. In this case 4.24. The analysis concludes with some 'Comments': 'Strong start, temporal and frontal activity throughout'. 'Music and visuals create a building response' and 'Product is represented in largest peaks, strong attention until end of spot.' Sands' research into measuring the 'brain's response to advertising' has resulted in patent pending software (Neuromedia ${ }^{\mathrm{TM}}$ ) that analyses and scores media by a target subject group's engagement (The Sands Research Neuro Engagement Score ${ }^{\mathrm{TM}}$ or NES). The measurement of advertising effectiveness is however only one aspect of applied neuromarketing research. In the next section we consider neuromarketing researchers' claims to revolutionise practices of consumer and market research. 


\section{Neuromarketing's revelatory potential}

Our analysis of claims about the revolutionary potential of neuromarketing is based on a preliminary analysis of key academic, professional and popular texts. These provide an introduction to and an overview of neuromarketing as well as critical discussion of its potential for market research. We select these texts because they aim to convince marketing academics and professionals that there is a valuable alternative to contemporary market research methods. Our selection is also informed by neuromarketers' own recommendations of 'introductory texts' to their peers and to potential clients, as evident from an online neuromarketing discussion group. ${ }^{7}$ It is these introductions and characterisations of neuromarketing that we now examine in some detail. We supplement our analysis of these texts with extracts taken from media reportage on neuromarketing.

Our analysis uses a version of Dorothy Smith's $(1978,1987)$ textual analysis. Smith's approach highlights the importance of analysing the social organization of a text in authorising its facticity. What organisational features of the text give rise to its reading as a factual account (Smith 1978, 33)? She asks in particular:

(1) How is a given version of an account authorized as that version which can be treated by others as factual?

(2) Who is allocated the privilege of definition?

(3) How are other possible versions or sources of possible disjunctive information ruled out?

These aspects of authorization can be read as giving experts a privileged status versus the reader of the account. Hence, the social organization of a factual account may place the reader at a disadvantage (Smith 1978, 51). In a second step Smith notes the 
importance of contrast structures $(1978,39$, see also 40-47, 51). By this she means that it is crucial to take notice of descriptions of events, behaviour etc. that are preceded by a statement which supplies the instruction for how to see that event or behaviour as different/contrasting to the norm or current practice. We consider Smith's approach especially appropriate to the task of illuminating the performative work of 'factual' descriptions of scientific results - in order to discover the nature and identity of the consumer(s) inscribed in these texts. From a Dorothy Smith inspired textual analysis perspective, texts perform (or enact) a community of readers and actors and thus adequate subject positions. Like Smith, we seek to show how the texts under consideration achieve acceptability as factual accounts and, in so doing, provide for a depiction of the identities, relationships, expectations and associations of consumers and consumer behaviour.

\section{Academic accounts of neuromarketing's potential}

We chose three academic texts that aim to introduce novices to neuromarketing: two are published in academic marketing journals (Fugate 2007; Hubert and Kenning 2008) and one in a neuroscience journal (Ariely and Berns, 2010). The first text is

'Neuromarketing: a layman's look at neuroscience and its potential application to marketing practice' (2007) written by Douglas Fugate, a Professor of Marketing at Western Kentucky University, USA. The abstract states that the purpose of the paper is to 'briefly cover the origins of neuromarketing, explain the process in layman's terms, enumerate some of the findings in anecdotal form, and suggest future consumer behaviour research directions based on these findings' $(2007,385)$.

Fugate regards neuromarketing as an essential tool for ' ...peering into the brain of the typical consumer to actually watch physical surrogates of the consumer decision 
making process...' $(2007,385)$. In his view neuromarketing will remove uncertainty from market research and open up the 'black box' of consumer behaviour $(2007,385)$. He contrasts neuromarketing with traditional methods and finds that whereas these have tended to base explanations of market behaviour on inference, neuromarketing can '... use science to locate consumers' buy button...' $(2007,385)$. Fugate notes that one of the key benefits of neuromarketing is that it 'avoids the problem of relying heavily upon subjects' self-reports when it is highly unlikely that even the most determined subject could accurately articulate his or her crucial subconscious motives' (Britt cited in Fugate 2007, 386). Brain imaging however, allows for authentic (unbiased and internal) responses to marketing stimuli $(2007,387)$. In addition, Fugate asserts, '.. preliminary results complicate our standard assumptions about consumer choice mechanism by suggesting complex brain interactions, a much broader role for emotions, and a disconnect between conscious reasoning and internal preference' $(2007,387)$. Hubert and Kenning's (2008) paper - A Current Overview of Consumer Neuroscience - appeared as part of a special issue on the topic of neuromarketing for the Journal of Consumer Behaviour (Senior and Lee, 2008). The editors remark that Hubert and Kenning's introduction to neuromarketing research is 'a most excellent place to start for the uninitiated' $(2008,266)$. Early on in their article Hubert and Kenning describe consumers as a 'black box' into which investigators could not get insight using classical research $(2008,273)$. However, 'a more direct view into the black box of the organism should be feasible with the help of advanced techniques and methods of brain research that are now applied in the field of consumer neuroscience (Kenning et al., 2007a)' $(2008,273) .{ }^{8}$ One of the key benefits of such an approach, according to them, is that consumer neuroscience offers 'a more objective measure of individual responses to marketing stimuli' $(2008,287)$. In particular, in comparison to self-assessment methods, 
consumer neuroscience is said to offer a more objective perspective. In the authors' view

... self-assessment methods [...] rely totally on the ability of the respondent to describe and reconstruct feelings and thoughts [and] are very subjective. Many effects in the human organism that influence behavior are not perceived consciously; hence, the cognitive filter of the test taker may bias the results. For example, a person who has a temperature may determine that his body feels cold, even though the objective measurement of a clinical thermometer indicates that it is not. (Hubert and Kenning 2008, 273)

Relatedly, Hubert and Kenning say that the findings of 'self-assessment methods' can be influenced by strategic behaviour and social desirability. These can be eliminated in consumer neuroscience since 'the participating subjects have little to no influence on the measurement of their brain activity (Camerer et al., 2005)' (2008, 273). In addition to objectivity, Hubert and Kenning identify a key benefit of neuromarketing research, that 'researchers hope to gain specific new insights into unconscious and automatic processes that influence human behavior'. Furthermore, they suggest that

..., one important contribution of consumer neuroscience is the emphasis on emotions and their influence on consumer decision-making. Consumers are no longer considered as completely rational, because emotions, unconscious and automatic processes, play a central role in generating behavior (Bechara and Damasio, 2005; Camerer et al., 2005). (Hubert and Kenning 2008, 287)

The description of the consumer as a 'black box' and of neuromarketing's potential as an 'objective science' that can provide insights into consumer's unconsciousness processes and emotions, and ultimately into consumers' buying behaviour, echoes the themes found in Fugate's description of neuromarketing. However, using the broader and more ambiguous term 'self-assessment methods' (a term that is not clearly defined in the article) Hubert and Kenning do not explicitly 
criticise traditional market research methods such as focus group. They instead stress that consumer neuroscience is still a young field which should not be considered a challenge to traditional consumer research. In their words consumer neuroscience 'rather, $[\ldots]$ constitutes a complementing advancement for further investigation of specific decision-making behavior' $(2008,274)$.

The third article on neuromarketing's potential published by Ariely and Berns (2010) in the journal Nature Reviews Neuroscience aims to distinguish between legitimate hopes and neuromarketing hype. In their introduction the authors provide an overview of the most commonly used market research techniques and note that one hope is "that neuroimaging will reveal information about consumer preferences that is unobtainable through conventional methods' $(2010,1)$. As in the previous two articles discussed above, the authors explain that this hope is based on the assumption that

... people cannot fully articulate their preferences when asked to express them explicitly, and that consumers' brains contain hidden information about their true preferences. Such hidden information could, in theory, be used to influence their buying behaviour, so that the cost of performing neuroimaging studies would be outweighed by the benefit of improved product design and increased sales. In theory, at least, brain imaging could illuminate not only what people like, but also what they will buy. (Ariely and Berns, 2010, 1, emphasis added)

In the remainder of their paper the authors assess this hope and conclude that 'continuing developments in analytical tools for neuroimaging data - for example, MvPA [multi-voxel pattern analysis] — suggest that neuroimaging will soon be able to reveal hidden information about consumer preferences' (2010, 8). According to the authors, one of the benefits of MvPA methods is that these methods have the power to predict the individual choices of a subject based on statistical associations of complex activation patterns taking place when an individual choice is being made. Moreover, 'it 
does not depend on the vagaries of an experimenter interpreting the meaning of an activation map' $(2010,4)$.

All three academic texts contrast neuromarketing with traditional or other marketing research methods in order to establish neuromarketing as a viable alternative to understanding consumer behaviour. By fashioning this dichotomy between traditional and 'new scientific' (and objective) research methods, the authors emphasise that neuromarketing has access to emotional rather than purely rational purchasing reasons, as well as to unconscious rather than conscious motives. The hope of revealing hidden information is central to the case for generating and sustaining research in the field of neuromarketing.

In sum, we see that academic neuromarketing texts are organised to provide the reading that neuromarketing is a new market research technique that not only helps marketers better to understand consumers (and thus to sell more) but also offers a particular conceptualisation of the consumer based on brain imaging technology and neuroscientific research findings. This conceptualisation provides an image of the consumer as an entity that does not know why s/he buys certain products, whose purchasing decisions are largely motivated by subconscious forces. Hence, consumers' self-reports are portrayed as unreliable and brain imaging as the source of more accurate answers than revealed by existing techniques such as surveys, focus groups or interviews. Of particular interest here is the emphasis in these neuromarketing texts on consumers' lack of knowledge about their purchasing motives. This conceptualisation of the consumer as a 'black box', as unaware of his/her preferences and purchasing motives, is also prevalent in a popular account on neuromarketing that we reviewed. 


\section{Popular professional account of neuromarketing's potential}

Buy-ology: how everything we believe about why we buy is wrong (Lindstrom, 2008), is a popular book aimed at both marketing professionals and a wider audience with a general interest in branding, advertising and consumer behaviour. The author, Martin Lindstrom, describes himself as a branding and marketing expert advising top executives globally on how to build better and lasting brands. Lindstrom states that 'by 2003, it had become pretty clear to [him] that traditional research methods, like market research and focus groups, were no longer up to the task of finding out what consumers really think' $(2008,18)$. So he set out to conduct the largest neuromarketing study with an international team of neuroscientists interested in branding and marketing (Neurosense, Oxford, and NeuroInsight, Australia). The study took three years to complete, cost approximately $\$ 7$ million which was provided by eight multinational companies, comprised multiple experiments (102 fMRI scans and 1979 SST studies) and involved 2081 subjects from five countries (America, Germany, England, Japan and China) as well as 200 researchers, ten professors and doctors, and an ethics committee $(2008,11,12,34,36)$.

These invocations of the scale of the study, the corporate sponsorship and endorsement of the research, the latest technological equipment, and the research experts involved all help in authorising Lindstrom's account. By positioning himself as providing an overview of the neuromarketing study, Lindstrom's account achieves further authorisation: he summarises the researchers' findings from the position of a witness factually describing the experiments (e.g., description of the building in which experiments took place, how the subjects behaved before the scanning and the atmosphere during the fMRI experiments) (2008, chapter 1); his account provides for the reading of the author as a removed observer of the collaboration taking place 
between others. That Lindstrom is indeed a trustworthy witness can be attributed to his own expert status that he stresses repeatedly in the introduction and first chapter.

How is Lindstrom's text organised to portray the nature of consumers and consumer behaviour that has been revealed in his collaborative neuromarketing study ${ }^{9}$ ? Of special interest is the use of contrast structures in Lindstrom's account. Right on the first pages of his book Lindstrom maps out the key research problem that he and many other branding consultants are faced with: why are consumers drawn to a particular brand? For Lindstrom the answer lies 'somewhere in the brain' $(2008,2)$ and that is the main reason why '... as consumers, we can't ask ourselves these questions, because most of the time, we don't know the answers' $(2008,3)$. Yet,

... if marketers could uncover what is going on in our brains that makes us choose one brand over another - what information passes through our brain's filter and what information doesn't - well that would be key to truly building brands of the future. (Lindstrom 2008, 3)

From early on, the Lindstrom text depicts and subsequently repeats a contrast between consumers' and marketers' capacity to understand why people buy what they buy. Consumers are said to have limited access to their unconsciousness. By contrast, marketers pursuing neuromarketing are equipped with a 'window into the human mind' which will enable them to unlock 'the subconscious thoughts, feelings, and desire that drive the purchasing decisions we make each and every day of our lives' $(2008,3)$. The text repeatedly stresses that the ability to access the subconscious is a key advantage of neuromarketing research:

... neuromarketing isn't the answer to everything.... But the good news is that understanding of how our unconscious minds drive our behaviour is increasing $(2008,6)$ 
So I hope you enjoy [the book], learn from it, and come away from it with a better understanding of our Buyology - the multitude of subconscious forces that motivate us to buy $(2008,6)$

[The neuromarketing study] revealed the hidden truths behind how branding and marketing messages work on the human brain, how our truest selves react to stimuli at a level far deeper than conscious thought, and how our unconscious minds control our behaviour (usually the opposite of how we think we behave) (2008, 11, emphasis in original)

If I could help uncover the subconscious forces that stimulate our interest and ultimately cause us to open our wallets, the brain-scan study would be the most important three years of my life $(2008,16)$

It's not that we mean to lie -it's just that our unconscious minds are lot better at interpreting our behaviour (including why we buy) than our conscious minds are $(2008,19)$

The asserted contrast between conscious and unconscious mind also provides the main basis for the dismissal of traditional research techniques, which rely on consumers' active, verbal participation. Lindstrom thus notes, 'until today, the only way companies have been able to understand what consumers want has been by observing or asking them directly'. However, 'what people say on surveys and in focus groups does not reliably affect how they behave - far from it' (2008, 20-21, emphasis in original). Lindstrom argues for example that it is impossible for consumers to know why they do the things they do $(2008,18)$ :

That's why the true reactions and emotions we as consumers experience are more likely to be found in the brain, in the nanosecond lapse before thinking is translated into words. So, if marketers want the naked truth - the truth unplugged and uncensored, about what causes us to buy - they have to interview our brains (2008, 22). 
The excerpt ends with a rhetorical flourish that plays into the key contrast structure which is performed and repeated throughout the text, namely that between: old methods and new methods; conscious and unconscious motives; unreliable and reliable knowledge. The key entity performed by the text - the brain - is identified explicitly as the appropriate target for interrogation ('interview').

The text thus provides for the reading of neuromarketing as offering a better understanding of consumers' (unconscious) thoughts than other market research techniques, because these are premised on the (in Lindstrom's 2008, 19 view, false) idea that traditional market research techniques conceptualise consumers as rational actors who can articulate their feelings and motives. It is precisely this conceptualisation of the consumer as a rational, conscious actor who can articulate his/her feelings in interviews or focus groups that the text seeks to dispel. The description of neuromarketing research as a means to access consumers' unconscious, seemingly irrational behaviour hinges on the contrast between the figures of the consumer differentially enacted in neuromarketing (irrational) and traditional (rational) market research methods.

\section{Media accounts of neuromarketing's potential}

Similar to academic and popular professional accounts of neuromarketing's potential, news stories reporting on neuromarketing repeatedly describe consumers as unaware of their 'true' preferences and purchasing motives, either based on interviews with neuromarketers or references to neuromarketing research. Our analysis of neuromarketing news stories examined major titles of the international printed press that we sourced by means of a key word search (i.e. neuromarketing) from the database Lexis Nexis (accessed 15.7.2010) that offers full-text access to news, commentary, pictures and media transcripts from international news media. We concentrate on the 
English-speaking media and started sourcing neuromarketing news stories from 2000 onwards. Limiting our search to major world newspapers we found 96 news stories that contained the term neuromarketing since 2003 . For the purpose of a focused preliminary analysis we selected eleven neuromarketing news stories ${ }^{10}$. Our preliminary analysis shows that neuromarketing is consistently described in all accounts as a 'new' market research technique that can offer companies a way 'to understand how consumers really respond to marketing and advertising' (Brat 2010). Neuromarketing is compared in these accounts to traditional market research techniques, such as the interview, focus group or questionnaire, which are described as having a limited usefulness because they do not fully capture consumers' unconscious responses. The subsequent quotes capture this problem/solution relationship succinctly:

Traditional market research is fraught with bias and imprecision, which forces companies to fall back on hunches and rules of thumb. But thanks to recent breakthroughs in brain science, companies can now actually see what goes on inside our minds when we shop. Teams of academic and corporate neuromarketers have begun to hook people up to functional magnetic resonance imaging (fMRI) machines to map how their neurons respond to products and pitches. (Carr 2008, emphasis added)

Maureen Duffy, Chief executive of the NMA [Newspaper Marketing Agency] is convinced that Brain Wave Science is going to be able to reach parts of the consumer psyche that other forms of advertising research can't. She says: 'Quite simply, most advertising research relies upon consumers being able to tell us what they recognise and to then articulate what response they had to the ads and ultimately to the brand. This can be challenging. Only by getting inside the minds of consumers in a rigorous manner can we really achieve this. (Ahuja 2006, emphasis added)

Conventional techniques for learning consumer preferences are notoriously inadequate, Mr McPartlin [Senior vice president of Lieberman Research Worldwide] said. The traditional methods that companies use to explore consumer 
preferences do not always reflect actual buying patterns. 'You use surveys when you want to test something - the reaction to an ad, package, new product name, or design,' he said. 'You ask questions scaled to gauge the response. But the scales are a blunt tool, ' he said. ' They cannot capture the emotional responses beneath consumer preferences'.

Complicating matters further, in focus groups, some people want to please, others to dominate - urges that can influence their choices. In interviews, consumers often say what they think the interviewer wants to hear. ...

Brain imaging experiments cut through these problems, Mr. McPartlin said, making it possible for companies to see more quickly and accurately what their customers want, like and feel that they need. (Blakeslee 2004, emphasis added)

Drawing on Smith's concept of contrast structures we again see how traditional market research is described as imprecise in the sentence that immediately precedes the statement which outlines the benefits of using neuromarketing research. We also see a performed contrast between consumers' and marketers' capacity to understand why people buy what they buy. This divide is premised on consumers' limited access to their unconsciousness. Marketers pursuing neuromarketing are however equipped with a 'window into the human mind' (see Lindstrom 2008, 3) which will enable them to unlock subconscious thoughts, feelings, and desires that drive consumption.

Or as another neuromarketing news story put it 'unlike the people answering questionnaires or participating in focus groups, brain waves don't lie. An activity spike in the left prefontal cortex ... would suggest the subject is attracted to the brand image or message' (Wells, 2003). This depiction of the consumer as non-knowledgable is premised on the description that consumers do not know why they buy something whereas consumers' brains can provide objective answers. In other words, consumers and their behaviour are portrayed as essentially constituted by their brains. As such we detect a prevalence of brainhood (Vidal 2005; Ortega and Vidal 2007; Vidal 2009) in 
these accounts as it is within the brain that consumers' preferences and desires can be located.

Based on our analysis of selected neuromarketing texts, we thus see that the depiction of consumers as lacking knowledge is a vital strategy for marketers to bypass consumers' verbal accounts and to justify researching otherwise inaccessible consumer knowledge. By promising to reveal the hidden causes of buying behaviour a set of expectations accompanies the practice and tools of neuromarketing that can be deemed crucial for creating, developing and possibly sustaining new knowledge of consumers. At the same time, only a particular community/group of experts (neuromarketers) can be entrusted to reveal these hidden causes using brain imaging technology. The important corollary is that the technology and its expert operators thereby become accountable for revealing the causes of purchasing decisions and that the human subject is secondarised as an object of research.

\section{Technologies of ironic revelation}

How then to make sense of these features of neuromarketing? It is useful first to consider neuromarketing practices in terms of similar technologies for bringing to revelation various hidden thoughts, feelings, opinions and other broadly cognitive and psychological phenomena. In this section we review examples which bear comparison with neuromarketing.

Signe Vikkelsø (forthcoming) discusses the role of technologies for materialising or provoking to appearance underlying phenomena in particular relation to psychoanalysis. She emphasises the importance of material artefacts, for example Sigmund Freud's couch, in making the unconscious a tangible phenomenon. The psychoanalyst's couch became a standardised requisite of professional practice. It was 
an important means of allowing the patient to relax, encouraging him/her to enter a state whereby inner thoughts, past experiences and feelings may more easily come to the surface. These otherwise hidden features of the patient's subconsciousness were thus made available. The couch had a central role in enacting key ontologies of the psychoanalytic experience: which past feelings, persons, parents, events could be relevantly brought into relation with feelings of anxiety, depression and so on. Significantly, the couch helps background the knowing subject: the patient does not (or does not so readily) have access to his/her subconsciousness except when lying on the couch.

Andrew Balmer (2010) examined the historical evolution and usage of the polygraph. As part of a variety of devices for revealing the truth, the polygraph is a form of confessional technology for bringing to the surface what an individual may be concealing, by means of monitoring nervous reactions, for example by changes in electrical resistance between fingers induced by sweating, in response to various stimuli, most usually in the form of questions. Whereas the material technologies of psychoanalysis are designed to reveal what the individual may have forgotten, or be unaware of, or is inadvertently (subconsciously) repressing, the material technology of the polygraph is more usually designed to reveal what an individual is actively concealing. The deep (but, as Balmer shows, historically variable) presumption is that the truth is prepotent. That is, the truth underlies actions, vocalisations, protestations and other superficial phenomena, and is the 'natural' state to which a human has automatic recourse when, for example, he or she is 'off their guard'. The technology of the polygraph works the ironic juxtaposition of surface performance and hidden truth. Javier Lezaun (2007) argues that the focus group can be understood as a pervasive technology of social investigation whereby group dynamics are used to bring 
into existence a series of relevant individual opinions. Lezaun describes in particular the technical and managerial skills of focus group moderators in leading 'the focus group to a useful outcome (of which their subjects are ignorant)' $(2007,141)$. He argues, against the view that opinions are unproblematic objects, that we need to know much more about how something comes to be counted as an opinion, about 'the conditions of possibility for something to become an opinion' $(2007,147)$. The focus group has to be understood as a machinery for the elicitation of individual opinions. In its operation, the moderators have to safeguard against a whole series of aspects of group dynamics which might unduly influence or distort the identification of individuals' authentic opinions. They have to 'formulate an image of the social order most conducive to the expression of authentic individual opinions' $(2007,140)$.

In all these examples we see how a particular technological form purports to reveal aspects of individual consciousness which otherwise lay hidden. The revelation is ironic in the particular sense that it depends on the achieved contrast between what appears to be the case - the patient's symptoms or account, the response given by the lying subject - and what turns out to be the case as a result of the application of the technology - the hidden underlying causes of symptoms, the hidden or concealed truth. Many technologies have a revelatory function of one kind or another: here we are especially interested in those that emphasise an ironic contrast. In line with much recent STS theorising and especially in the analysis of financial markets (e.g., Knorr Cetina and Preda 2005; MacKenzie, Muniesa, and Siu 2007; Callon, Millo, and Muniesa 2008) and of medical imaging (e.g., Beaulieu 2000; Dumit 2000; Roepstorff 2001; Beaulieu 2002; Roepstorff 2002; Cohn 2004; Dumit 2004; Joyce 2005; Prasad 2005; Alač 2008; Burri and Dumit 2008; Burri 2008), we agree that these aspects of psyche are performed rather than merely revealed by the technologies. However, it is important to note that 
the performance of aspects of psyche also involves the simultaneous constitution of related entities, which keep the performance in place. For example, the technology of the couch not only performs the subconsciousness but simultaneously enacts or constitutes the figure of the patient, the analyst as well as other possibly relevant entities (parents, siblings, memories, events and so on).

The importance of co-constituted or co-enacted entities is evident when we understand revelatory technologies as devices which depend for their effect on a redistribution of accountability relations. Accountability relations are those connections between entities which describe a form of accountability or responsibility between them. For example, it is an important part of traffic regulation and management that drivers are held to be in an accountability relation with their vehicle. Specifically, drivers can be held to account for the speed (for example, too fast or too slow) and position (for example, whether or not properly parked) of their vehicle. As Woolgar and Neyland (forthcoming) show, the assertion of accountability relations requires considerable work to establish and maintain appropriate connections. For example, whether or not the speeding car actually belongs to the driver - whether or not it is actually 'their' car - is the focus of just one aspect of a well institutionalised bureaucratic process for fashioning the accountability relation in question (and thence bringing legal sanctions into play).

In the case of the psychiatrist's couch, the co-enactment of the psychiatrist and the patient's subconsciousness is important to the psychiatrist's claim to authority as a guide to the revelation of that subconsciousness. In most kinds of psychotherapy, the therapist's role as guide takes the form of a relatively passive participant in revelation; the therapist is important in helping the patient towards the recognition of their subconsciousness, but not for the contents of what is revealed; and effective 
psychotherapy is that where the patient comes to realisation through their own process of reflection and introspection. In the case of the polygraph, the enactment of the merely technical character of the machine is important to its bearing accountability for the revelation of the truth or lie.

How does this work in the case of neuromarketing? Clearly we can understand neuroscience, fMRIs etc. as technologies for materialising, or provoking to appearance, underlying phenomena. The key additional point is that these underlying phenomena are given value by contrast with what is otherwise available. Thus, as cited above neuromarketing promises to 'avoid the problem of relying heavily upon subjects' self reports when it is highly unlikely that even the most determined subject could accurately articulate his or her crucial motives' (Britt cited in Fugate 2007: 386). Accountability for subjects' motives passes from the subjects to the technology and its operatives - and maybe increasingly in the future to software packages that are deemed more reliable than experts, for example in the case of multi-voxel pattern analysis.

We suggest that this understanding of neuromarketing devices in terms of the redistribution of accountability relations also illuminates two further key features of neuromarketing: 1) the nature and dynamics of criticism and responses to criticism and 2) shifts in the criteria of evaluation of the effectiveness of neuromarketing.

A common popular reaction to neuromarketing and a point made by critics of neuromarketing is that the technology is not reliable. It is 'not possible', it is said, to extrapolate (accurately) from measurements of blood flow in the brain to states of the unconsciousness, product preference etc. It is important to note that this is construed as a technical rather than a conceptual criticism. The criticism does not challenge the concept of the duality 'brain-behaviour'; it instead suggests the connection between the two is inadequate. So the construal of the problem as merely technical leaves the binary 
duality intact by proposing that the problem is to do with the removal of interceding difficulties. It reinforces, after Garfinkel (1967), the efficacy of the 'documentary method of interpretation'. In this way, curiously, the criticism even reinforces the possibility of the dualism. More and better brain scanners will overcome these difficulties and secure the proposed connection between brain and behaviour. Thus the potentially fatal flaw in the very concept of the neuro is instead transformed into an appeal for more resources.

Now, in principle, these technical problems could be thought so severe as to make the use of this technology, and hence neuromarketing as a whole, unwarranted. It could be seen as irrational to rely upon a technology with such extensive technical problems. However, we know that assessments of technology also (or perhaps, more usually) depend on visions of a future in which the technology works, that is, of a time when what turn out to have been temporary technical problems have been overcome. Thus, companies feel encouraged to invest in neuromarketing against the promise of future improvements in the technology. This makes their decision seem more rational. But other considerations are often involved. For example, companies often take the view that even if the technology is not proven it might be unwise to be 'left behind'. In addition, we know that stories about the workability (and potential workability) of new technologies have functional value across diverse networks of interested parties. For example, the literature on management fads and fashions shows us that, whether or not a particular technique (management tool) works, it can have significant value as a form of discourse. Accounts of a new technology can act as narratives which enable story telling between different constituencies (Simakova and Neyland 2008): tales of neuromarketing futures have currency between managers, consultants, gurus, academics, and advertising agencies. 
So criticisms of neuromarketing can be countered or downplayed by, in effect, relocating accountability relations in the future (Rappert 2001). The accountability for adequately knowing the consumer is thereby assigned to future instantiations of the technology (and its operatives). In so doing, the more difficult general problem - what might sustain the conceptual distinction between person and brain - is dissipated and thereby becomes intractable. The problem belongs to everyone and no one.

We thus see that the accountability relations associated with the 'workingness' of neuromarketing are displaced. In its guise as a wholly laboratory based venture, 'workingness' corresponds to the adequacy of neuroimaging as determined by a community of scientists. This will include some consideration of 'why'. In the context of advertising agencies and product development companies, 'workingness' is instead associated with its value for the discourse of marketing and advertising ('it seems to work'). Different constituencies constitute different sets of accountability relations.

This consideration of accountability relations also helps explain the curious recent social phenomenon which we have come to call 'the brain moment'. Increasingly, during academic (and other) presentations, we noticed the unexpected appearance of the image of the brain. At a point during the presentation an image, typically a coloured cross section image of the cranium, suddenly appears on a powerpoint slide. Our apprehension of this appearance as 'sudden' reflects the sense that the reference to the brain is a non sequitur, for example, when what might easily be anticipated as a developing argument about cultural variation in reaction to artefacts, is turned into an argument about how the brain is responsible for these reactions. The introduction of the brain seems sudden in this situation because an unexpected new set of accountability relations are being invoked. The experience is that a whole new and unfamiliar array of research and research claims are being posited as relevant to the 
matter at hand. In this particular example, the introduction of the brain represents a putative shift in who knows best about the consumer from the anthropologist of consumption to the neuroscientist.

\section{Conclusion}

As a contribution to the emerging field of market studies, what does our study have to say about the genesis and operation of 'neuromarkets'? Neuromarketing is unquestionably a term which enjoys widespread and, as far as we can see, increasing usage. But in what sense can there said to be 'neuromarkets'? Clearly this is a somewhat different set of 'market' activities as compared with say the used car market, or the commodities market: neuromarkets are not about selling neuros, in the direct sense. They are instead about the use of the figure of the neuro to do marketing (of, as it seems, just about any commodity or service one can imagine). Consultants, self styled gurus, advertising agencies and entrepreneurs are in effect marketing the figure of the neuro both to each other and to consumers. In other words, neuromarkets involve the promotion and exchange of the idea of the neuro, as a kind of proxy for the brain, which thereby achieves a commodity like status.

Crucially, as we have argued, the neuro is the vehicle whereby ironic revelation is made possible. With the aid of appropriate technologies, the neuro is claimed to be the means of bringing to revelation what the consumer does not know and/or cannot say about herself. The consumer becomes a cipher. She becomes an entity which not only 'does not know its own mind' but which thereby also attracts a variety of agencies which claim to speak on its behalf. The consumer becomes 'secondarised', that is, is rendered a passive secondary being, an unknowing, unreliable entity who (which) can 
only (reliably) be spoken on behalf of by others with access to the appropriate technology.

Technologies of ironic revelation do not act in isolation. They are rather part of an assemblage of devices, neuromarketing texts, the proposals and portfolios of marketing and advertising agencies, popular media reports and comments and so on. It is likely these other devices similarly support the overall picture of 'secondarisation'. The consumer becomes a figure driven by his/her emotions rather than by rational choice. And, to the extent that this image of the consumer holds sway and is communicated via the media to the wider public, what are the implications for future consumption? Will (neuro)consumers of the future draw on this repertoire to justify their own behaviour? To absolve themselves from responsibility for not recycling, or for continuing to eat unhealthy food?

These considerations touch upon a much larger general question beyond the remit of this paper: why is this form of reductionism rampant at this point of our history? What explains the general preference for accounts of human behaviour which privilege the gene, the brain and so on, over the person? It is difficult at this point to anticipate the kind of explanation which might satisfactorily address questions of this magnitude. It is clear, however, as we have tried to suggest, that close attention to the detailed operation of market practices can help point us in the right direction. 


\section{References}

Advertising Research Foundation (ARF). 2011. NeuroStandards Collaboration Project. New York: ARF.

Ahuja, A. 2006. Little grey sells. The Times, 7 December 2006.

Alač, M. 2008. Working with Brain Scans: Digital Images and Gestural Interaction in FMRI laboratory. Social Studies of Science 38, no. 4: 483-508.

Andersson, P., K. Aspenberg, and H. Kjellberg. 2008. The configuration of actors in market practice. Marketing Theory 8, no. 1: 67-90.

Araujo, L. 2007. Markets, market-making and marketing. Marketing Theory 7: 211-226.

Ariely, D., and G. S. Berns. 2010. Neuromarketing: the hope and hype of neuroimaging in business. Nature Reviews Neuroscience 11: 284-292.

Balmer, A. 2010. Lessons from polygraphy: Will fMRI lie detection be used in the US legal system? Paper presented to Medical Anthropology Discussion Group, Green Templeton College, University of Oxford.

Barrey, S., F. Cochoy, and S. Dubuisson-Quellier. 2000. Designer, packager et merchandiser: trois professionnels pour une même scéne marchande. Sociologie du Travail 42, no. 3: 457-482.

Beaulieu, A. 2000. The brain at the end of the rainbow: The promise of brain scans in the research field and in the media. In Wild Science: Reading Feminism, Medicine and the Media, ed. J. Marchessault and K. Sawchuk, 39-54.London: Routledge.

Beaulieu, A. 2002. Images are not the (only) truth: Brain mapping, visual knowledge and iconoclasm. Science, Technology and Human Values 27, no. 1: 53-86.

Blakeslee, S. 2004. If you have a buy-button in your brain, what pushes it? The New York Times, 19 October 2004.

Brat, I. 2010. Campbell gets under the skin for soup sales pitch. The Australian, 19 February 2010.

Burne, J. 2003. A probe insided the mind of the shopper. The Financial Times, 28 November. 2003

Burri, R., and J. Dumit. 2008. Social studies of scientific imaging and visualization. In Handbook of Science and Technolgoy Studies, ed. E. J. Hackett, O. Amsterdamska, M. Lynch and J. Wajcman, 297-317. Cambridge, MA: MIT Press. 
Burri, R. V. 2008. Doing distinctions: Boundary work and symbolic capital in radiology. Social Studies of Science 38: 35 - 62.

Callon, M. 1986. Some elements of a sociology of translation: domestication of the scallops and the fishermen of St Brieuc Bay. In Power, action and belief: A new sociology of knowledge?, ed. J. Law, 196-233, London: Routledge.

Callon, M. 1998a. Introduction: The embededness of economic markets in economics. In The laws of the market, ed. M. Callon, 1-57. Oxford: Blackwell.

Callon, M., ed. 1998b. The laws of the market. Oxford: Blackwell.

Callon, M., Y. Millo, and F. Muniesa, ed. 2008. Market devices. Oxford: Blackwell.

Carr, N. 2008. Neuromarketing could make mind reading the ad-man's ultimate tool. The Guardian, 3 April 2008.

Cochoy, F. 1998. Another discipline for the market economy: Marketing as a performative knowledge and know-how for capitalism. In The laws of the market, ed. M. Callon, 194-221. Oxford: Blackwell..

Cochoy, F. 2007. A sociology of market-things: on tending the garden of choices in mass retailing. In Market devices, ed. M. Callon, Y. Millo and F. Muniesa, 109129. Oxford: Blackwell.

Cochoy, F. 2008. Calculation, qualculation, calqulation: shopping cart arithmetic, equipped cognition and the clustered consumer. Marketing Theory 8, no. 1: 1544.

Cohn, S. 2004. Increasing resolution, intensifying ambiguity: an ethnographic account of seeing life in brain scans. Economy and Society 33, no. 1: 54-76.

Dumit, J. 2000. When explanations rest: 'Good-enough' brain science and the new sociomedical disorders. In Living and Working with the New Medical Technologies: Intersections of Inquiry, ed. M. Lock, A. Young and A. Cambrosio, 209-232. New York: Cambridge University Press.

Dumit, J. 2004. Picturing personhood: Brain scans and biomedical identity. Princeton, N.J.: Princeton University Press.

Editorial. 2004. Brain scam? Nature Neuroscience 7, no. 7: 683.

Ehrenberg, A. 2004. Le sujet cerebral. Esprit 309: 130-155.

Fugate, D. L. 2007. Neuromarketing: A layman's look at neuroscience and its potential application to marketing practice. Journal of Consumer Marketing 24, no. 7 : 385-394.

Garfinkel, H. 1967. Studies in Ethnomethodology. Englewood Cliffs, NJ: Prentice-Hall. 
Hackley, C. 2002. The panoptic role of advertising agencies in the production of consumer culture. Consumption, Markets \& Culture 5, no. 3: 211-229.

Harris, P., and A. Flood. 2010. Literary critics scan the brain to find out why we love to read. Guardian, 11 April 2010.

Hotz, R. L. 2005. Mapping the mind: searching for the why of buy. The Los Angeles Time, 5 February 2005.

Hubert, M. and P. Kenning. 2008. A current overview of consumer neuroscience. Journal of Consumer Behaviour 7: 272-292.

Joyce, K. 2005. Appealing images: Magnetic resonance imaging and the production of authoritative knowledge. Social Studies of Science 35, no. 3: 437-462.

Kjellberg, H. 2008. Market practices and over-consumption. Consumption, Markets \& Culture 11, no. 2: 151-167.

Kjellberg, H., and C.-F. Helgesson. 2007. On the nature of markets and their practices. Marketing Theory 7: 137-162.

Knorr Cetina, K., and A. Preda, eds. 2005. The sociology of the financial markets. Oxford: Oxford University Press.

Latour, B. 1993. We have never been modern. Cambridge, MA: Harvard University Press.

Lee, N., A. J. Broderick, and L. Chamberlain. 2007. What is 'neuromarketing'? A discussion and agenda for future research. International Journal of Psychophysiology; Special Edition: Cognitive Neuroscience: Contributions from Psychophysiology 63, no. 2: 199-204.

Lezaun, J. 2007. A market of opinions: the political epistemology of focus groups. The Sociological Review 55, no. S2: 130-151.

Lindstrom, M. 2008. Buy-ology. How Everything We Believe About Why We Buy is Wrong. London: Random House Business Books.

Maasen, S., and B. Sutter, ed. 2007. On willing selves. Neoliberal politics vis-a-vis the neuroscientific challenge. Basingstoke: Palgrave Macmillan.

Macdonald, E. K., and M. Uncles. 2007. A conceptualization and analysis of the 'savvy consumer'. Journal of Marketing Management 23, no. 5-6: 497-517.

MacKenzie, D. 2003. An equation and its worlds: Bricolage, exemplars, disunity and performativity in financial economics. Social Studies of Science 33: 831-868.

MacKenzie, D., F. Muniesa, and L. Siu, ed. 2007. Do economists make markets? On the performativity of economics. Princeton: Princeton University Press. 
Medina, J. 2004. The neurobiology of the decision to buy. Psychatric Times. October: $31-34$

Mol, A. 2002. The body multiple: Ontology in medical practice. Durham: Duke University Press.

Nadesan, Majia Holmer. 2002. Engineering the entrepreneurial infant: Brain science, infant development toys, and governmentality. Cultural Studies 16, no. 3: 401432.

Ortega, F., and F. Vidal. 2007. Mapping the cerebral subject in contemporary culture. RECIIS - Electronic Journal of Communication, Information \& Innovation in Health 1, no.2: 255-259.

Packard, V. 1957/1981. The hidden persuaders. Harmondsworth: Penguin.

Prasad, A. 2005. Making Images/Making Bodies: Visibilizing and Disciplining through Magnetic Resonance Imaging (MRI). Science, Technology \& Human Values 30, no. 2: 291-316.

Rappert, B. 2001. The Distribution and Resolution of the Ambiguities of Technology, or Why Bobby Can't Spray. Social Studies of Science 31, no. 4: 557-591.

Roepstorff, A. 2001. Brains in scanners: An Umwelt of cognitive science. Semiotica 134, no. 1: 747-765.

Roepstorff, A. 2002. Transforming subjects into objectivity. An ethnography of knowledge in a brain imaging laboratory. FOLK, Journal of the Danish Ethnography Society 44: 145-170.

Rose, N. 2003. Neurochemical selves. Society 41: 46-59.

Rose, N. 2006. The politics of life itself: Biomedicine, power, and subjectivity in the twenty-first century. Princeton: Princeton University Press.

Schneider, T. forthcoming. Review of Ernest Dichter and Motivation Research: New Perspectives on the Making of Post-War Consumer Culture, edited by Stefan Schwarzkopf and Rainer Gries. History of the Human Sciences.

Schüll, N. and C. Zaloom. 2011. The shortsighted brain: Neuroeconomics and the governance of choice in time Social Studies of Science. Published online 8 March 2011: DOI: 10.1177/0306312710397689.

Schwarzkopf, S. and R. Gries, ed., 2010 Ernest Dichter and Motivation Research: New Perspectives on the Making of Post-War Consumer Culture. Basingstoke: Palgrave Macmillan. 
Senior, C., and N. Lee. 2008. A manifesto for neuromarketing science. Journal of Consumer Behaviour 7, no. 4-5: 263-271.

Shapin, S., and S. Schaffer. 1985. Leviathan and the air-pump: Hobbes, Boyle, and the experimental life. Princeton, N.J.: Princeton University Press.

Simakova, E., and D. Neyland. 2008. Marketing mobile futures: Assembling constituencies and creating compelling stories for an emerging technology. Marketing Theory 8: 91-116.

Smith, D. 1978. 'K is mentally ill': The anatomy of a factual account. Sociology 12, no. 1: $23-53$.

Smith, D. 1987. The everyday world as problematic: A feminist sociology. Toronto: University of Toronto Press.

Vidal, F. 2005. Le sujet cérébral: une esquisse historique et conceptuelle. Psychiatrie, sciences humaines, neurosciences 3, no. 11: 37-48.

Vidal, F. 2009. Brainhood, anthropological figure of modernity. History of the Human Sciences 22, no. 1: 5-39.

Vikkelsø, S. forthcoming. The fragility of a robust therapeutic technique: The case of Bion's experience group. Theory \& Psychology.

Wells, M. 2003. In search of the buy button. Forbes. 1 September 2003

Wilson, M. R., J. Gaines, and R. P. Hill. 2008. Neuromarketing and consumer free will. Journal of Consumer Affairs 42, no. 3: 389-410.

Woolgar, S., and D. Neyland. forthcoming. Mundane Governance: technology, ontology and accountability. Oxford: Oxford University Press.

\section{Notes}

\footnotetext{
${ }^{1}$ See also Ehrenberg's (2004) earlier use of the term 'sujet cerebral'.

${ }^{2}$ Actor Network Theory (ANT) developed by French sociologists,Bruno Latour and Michel Callon, and British sociologist John Law articulates the generalised principle of symmetry. This principle can be described as a methodological guideline to follow and describe any element in a network, human and non-human (see, for instance, Callon 1986)

${ }^{3}$ For example see the following website: http://www.sandsresearch.com/default.aspx [accessed 12.10.10].

${ }^{4}$ For a discussion of potential similarities and differences between Motivation Research and neuromarketing, see Schneider (forthcoming).

${ }^{5}$ For instance, GlaxoSmithKline, Bertelsmann, Unilever, Intel, McDonald's, Proctor \& Gamble, MTV and DaimlerChrysler (Lindstrom 2008; Wells 2003; CBS Broadcasting Inc. 2009).

${ }^{6}$ http://www.neurosciencemarketing.com/blog/articles/super-bowlbrain-movies.htm [accessed 13.10.10]
} 
${ }^{7} \mathrm{We}$ are members of the neuromarketing discussion group that is part of a business-oriented social networking site, which is mainly used for professional networking. The discussion group has approximately 1300 members who discuss a broad range of topics related to neuromarketing publications, current research and media reportage of neuromarketing.

${ }^{8}$ Hubert and Kenning suggest a distinction between a) consumer neuroscience as the scientific proceeding, and b) neuromarketing as the application of these findings within the scope of managerial practice.

${ }^{9}$ We limit our analysis of Lindstrom's book to the introduction and chapter one.

${ }^{10} \mathrm{~A}$ list of reviewed neuromarketing news stories:

1. Brat, Ilan (2010) Campbell's gets under your skin. The Australian, February 19, 2010, p. 22.

2. Toller, C. (2009) The push for pull; inventory-crunched retailers are asking consumers to choose the products they want. But what we say we like isn't always what we buy. The Globe and Mail (Canada), September 25, 2009 p. 13.

3. Carr, N. (2008) Neuromarketing could make mind reading the ad-man's ultimate tool. The Guardian.

4. Wells, J. (2008) The Brain Guy wants to get inside your head, The Globe and Mail (Canada), March 15,2008 , p. B4

5. Lindstrom, M. (2008) Why 'Idol' works for Coke but not for Ford; Neuromarketing study suggests carmaker made a $\$ 26$ million mistake by failing to establish a purpose for its presence. Advertising Age, November 17, 2008, p. 19.

6. Frazier, M. (2007) Hidden Persuasion or junk science, Advertising Age, September 10, 2007, p. 1.

7. Ahuja, A. (2006) Little grey sells, The Times (London), December 7, 2006, p. 4.

8. Lewis, Carol (2005) Marketeers turn on to brain waves. The Times (London), March 31, 2005.

9. Blakeslee, S. (2004) If you have a buy-button in your brain, what pushes it? The New York Times.

10. Burne, J. (2003) A probe insided the mind of the shopper. The Fincancial Times.

11. Wells, M. (2003) In Search of the Buy Button. Forbes. 